\section{Suggested Actions}

- Evaluate energy costs, process load and production requirements to determine the economic feasibility of LFL monitoring equipment.

- Examine process energy requirements to confirm the flammable solvent load. If this load has changed over time, ventilation rates may need to be adjusted.

- Using a booster oven can reduce the evaporation requirements in the main oven, thus reducing its exhaust requirements

- Consider a professional outside evaluation to determine the technical and economic feasibility of additional improvements including reducing wall losses, installing heat exchangers and fume incinerators, and recuperating exhaust air to capture the heat value of exhaust air.

- Check all relevant NFPA and other applicable codes, regulations, and standards before adding equipment or making adjustments and consider consulting with an expert.

\section{Resources}

\section{U.S. Department of Energy-}

For additional information on process heating system efficiency, to obtain DOE's publications and Process Heating Assessment and Survey Tool (PHAST) software, or learn more about training, visit the BestPractices Web site at www.eere.energy.gov/industry/ bestpractices.

\section{Use Lower Flammable Limit Monitoring Equipment to Improve Process Oven Efficiency}

Process heating applications involving flammable solvent removal use large amounts of energy to maintain safe lower flammable limits (LFL) in the exhaust air. National Fire Protection Association (NFPA) guidelines require the removal of significant amounts of exhaust air to maintain a safe, low-vapor solvent concentration. If LFL monitoring equipment is used to ensure proper vapor concentrations, these guidelines allow for less exhaust air removal. LFL monitoring equipment can improve the efficiency of the solvent removal process and significantly lower process energy requirements.

Flammable solvents used in industrial production processes are typically evaporated in industrial ovens. Higher oven temperatures evaporate solvent vapors more quickly, allowing for faster production. Because the vapors are flammable, the exhaust air is discharged (along with the heat) to prevent the accumulation of the vapors in the oven. As the oven temperatures increase, plants have to maintain higher ventilation ratios to reduce the solvent vapor concentration levels and maintain the respective LFL.

For example, the NFPA ventilation safety ratio for batch-loaded ovens operating below $250^{\circ} \mathrm{F}$ is $10: 1$ and xylol has an LFL of $1 \%$. Therefore, exhaust ventilation needs to be added to the vapor until the solvent concentration reaches $0.1 \%$, meaning that the plant has to exhaust 10 times the amount of air required by the process to meet the NFPA requirement. If the process operates above $250^{\circ} \mathrm{F}$, the required safety ratio rises to $14: 1$, the LFL goes down to $0.07 \%$, and the plant has to exhaust 14 times the amount of air required to keep the process from becoming flammable.

The non-uniform rate of solvent vaporization is one of the reasons why LFLs are so stringent. Solvent vaporization is inherently non-uniform mainly because of wall losses and load characteristics; this causes periodically high solvent concentrations in the oven during the vaporization process. As a result, safe ventilation ratios are calculated using the theoretical peak needs of ventilation based on the highest vapor concentrations that can accumulate during the vaporization process.

\section{LFL Monitoring Equipment}

LFL monitoring equipment can reduce energy used in solvent removal by adjusting the ventilation ratio according to the fluctuations in vapor concentration. The equipment continuously tracks the solvent extraction rate in real time and controls the rate of ventilation air based on real needs, thereby maintaining a safe ratio throughout the process. LFL monitoring equipment can employ several technologies including catalytic systems, infrared sensors, ionization systems and combustion sensors. LFL monitoring equipment has self-check functions and uses a calibrated test gas for periodic self-calibration. Because the vaporization process depends on the intake and exhaust air, linking the LFL controller to an adjustable speed drive on the exhaust system fan can improve process efficiency even further (damper adjustments can also be used). 


\section{Example}

The NFPA safety ventilation ratios are significantly lower when LFL monitoring equipment is used than when such equipment is absent. This lowers the energy requirements for the process because less air needs to be exhausted to keep the process from becoming flammable. For a continuous strip coating process requiring 46 gallons of xylol with a maximum oven temperature of $800^{\circ} \mathrm{F}$ and ambient air temperature of $70^{\circ} \mathrm{F}$, the safety ventilation ratio is $4: 1$ without LFL monitoring equipment. This results in an exhaust requirement of 8,330 standard cubic feet per minute and energy consumption of 6.7 million British thermal units (MMBtu) per hour. At a cost of $\$ 8 / \mathrm{MMBtu}$ assuming a two-shift operation, this process costs approximately $\$ 214,000$ annually. Installing LFL monitoring equipment would reduce the ratio to 2:1, halving the exhaust and energy requirements. Annual energy savings would total $\$ 107,000$. With an installed cost of $\$ 12,500$ for an LFL controller, the simple payback is very attractive at less than 1.5 months.

\section{References}

Hans L. Melgaard, "Substantial Energy Savings are Often Realized by Monitoring Process Oven Exhausts," Plant Engineering, November 1980

Improving Process Heating System Performance: A Sourcebook for Industry. U.S. Department of Energy and Industrial Heating Equipment Association. Download at http:// wwwl.eere.energy.gov/industry/bestpractices/techpubs_process_heating.html
BestPractices is part of the Industrial Technologies Program Industries of the Future strategy, which helps the country's most energy-intensive industries improve their competitiveness. BestPractices brings together emerging technologies and best energy-management practices to help companies begin improving energy efficiency, environmental performance, and productivity right now.

BestPractices emphasizes plant systems, where significant efficiency improvements and savings can be achieved. Industry gains easy access to near-term and long-term solutions for improving the performance of motor, steam, compressed air, and process heating systems. In addition, the Industrial Assessment Centers provide comprehensive industrial energy evaluations to small- and medium-size manufacturers.

FOR ADDITIONAL INFORMATION, PLEASE CONTACT:

EERE Information Center

1-877-EERE-INF

$(1-877-337-3463)$

www.eere.energy.gov

Industrial Technologies Program Energy Efficiency and Renewable Energy U.S. Department of Energy Washington, DC 20585-0121 www.eere.energy.gov/industry

\section{A Strong Energy Portfolio FOR A STRONG AMERICA}

Energy efficiency and clean, renewable energy will mean a stronger economy, a cleaner environment, and greater energy independence for America. Working with a wide array of state, community, industry, and university partners, the U.S. Department of Energy's Office of Energy Efficiency and Renewable Energy invests in a diverse portfolio of energy technologies. 